\title{
PREFERED SURGICAL TECHNIQUE USED BY ORTHOPEDISTS IN ACUTE ACROMIOCLAVICULAR DISLOCATION
}

\author{
Alexandre Yukio Nishimi ${ }^{1}$, Demetrio Simão Arbex ${ }^{1}$, Diogo lucas Campos Martins ${ }^{1}$, Carlos Vinicius Buarque de Gusmão ${ }^{2}$, \\ Roberto Rangel Bonglovanni ${ }^{1}$, Luciano Pascarelli ${ }^{1}$
}

1. Hospital IFOR, Shoulder and Elbow Surgery Group, São Bernardo do Campo, SP, Brazil.

2. Universidade Estadual de Campinas (Unicamp), Department of Orthopedics and Traumatology, Campinas, SP, Brazil.

\section{ABSTRACT}

Objective: To determine whether training on shoulder and elbow surgery influences the orthopedist surgeons' preferred technique to address acute acromioclavicular joint dislocation (ACD). Methods: A survey was conducted with shoulder and elbow specialists and general orthopedists on their preferred technique to address acute ACD. Results: Thirty specialists and forty-five general orthopedists joined the study. Most specialists preferred the endobutton technique, while most general orthopedists preferred the modified Phemister procedure for coracoclavicular ligament repair using anchors. We found no difference between specialists and general orthopedists in the number of tunnels used to repair the coracoclavicular ligament; preferred method for wire insertion through the clavicular tunnels; buried versus unburied Kirschner wire insertion for acromioclavicular temporary fixation; and time for its removal; and regarding the suture thread used for deltotrapezoidal fascia closure. Conclusion: Training on shoulder and elbow surgery influences the surgeons' preferred technique to address acute ACD. Level of Evidence V, Expert Opinion.

Keywords: Acromioclavicular joint/surgery. Surgical procedures, operative. Orthopedica. Surveys and questionnaires.

Citation: Nishimi AY, Arbex DS, Martins DLC, Gusmão CVB, Bongiovanni RR, Pascarelli L. Prefered surgical technique used by orthopedists in acute acromioclavicular dislocation. Acta Ortop Bras. [online]. 2016;24(5):249-52. Available from URL: http://www.scielo.br/aob.

\section{INTRODUCTION}

There are more than 60 procedures described for the surgical treatment of acute acromioclavicular dislocation (ACD). All techniques aim to restore joint congruence, which can be obtained via open or arthroscopic procedures, with anatomical or not anatomical reconstruction, and using various types of implants. ${ }^{1-5}$ To date, no technique proved superior to others from a clinical and radiological point of view. ${ }^{1-3,5-9}$ Therefore, the choice of technique to be used will depend on the surgeon's training, on the material available and personal preference. ${ }^{10}$ Basically, there are two populations of trained orthopedic surgeons that are able to surgically treat acute ACD: specialists in shoulder and elbow surgery, and general orthopedic surgeons. Specialization in shoulder and elbow aims to improve the technical and technological capabilities of the orthopedist. Thus, it is believed that specialization can modify the surgical and clinical reasoning of the orthopedists, influencing their decisions. The objective of this study was to determine whether training in shoulder and elbow surgery influences the choice of the surgical technique for the management of acute ACD. To this end, a questionnaire was applied to orthopedic specialists and general orthopedic surgeons, in order to determine the technical differences between these two groups of surgeons.

\section{MATERIALS AND METHODS}

The study was submitted for assessment by the institutional Research Ethics Committee and approved under protocol number 1627521. We interviewed orthopedists with and without specialization in shoulder and elbow surgery. Each orthopedist responded a questionnaire on the technique used and further details for the surgical treatment of acute ACD. (Annex 1)

Only orthopedists holding a title of specialist - Orthopedics and Traumatology Specialist (OTS) recognized by the Brazilian Society of Orthopedics and Traumatology (Sociedade Brasileira de Ortopedia e Traumatologia, SBOT) that have operated at least one acute ACD in the previous year were included in the sample. Orthopedists specialist (OTS) was defined as professionals with titles recognized by SBOT who have completed an internship in shoulder and elbow surgery accredited by the Brazilian Society of Shoulder and Elbow Surgery (Sociedade Brasileira de Cirurgia do Ombro e Cotovelo, SBCOC).

Statistical analysis was performed with SPSS 17.0 software,

All the authors declare that there is no potential conflict of interest referring to this article. 
which calculated absolute and relative frequencies for qualitative variables. We used the chi-square test or Fisher's exact test to assess the homogeneity between proportions. Was adopted $\alpha=0.05$ as significance level.

\section{RESULTS}

The questionnaire was applied to 75 orthopedists which matched the inclusion criteria, 30 specialists (40\%) and 45 generalists (60\%).

Most generalists operated up to five ACD the previous year; while most specialists operated more than five ACD specialists the previous year, and they integrate the group with the largest number of orthopedic surgeons who operated more than 10 ACD cases in that period. (Table 1)

There were no differences between groups regarding OTS-SBOT time, in years, of the OTS-SBOT time was equal to shoulder and elbow surgery time for the specialists group. (Table 2)

The most used technique among specialists and generalists was suture-anchor modified Phemister's ${ }^{11}$ technique or wiring to repair coracoclavicular ligaments. ${ }^{12}$ Of the modifications of Phemister's technique, the most used among generalists was the one with anchors; and the most used among specialists was wiring. Considering the technics alone (separating Phemister's changes), the most used among the specialists was the endobutton technique. On the contrary, no non-specialist orthopedist used the endobutton technique on acute ACD surgery. (Table 3)

Both specialists and generalists who used Phemister's modified techniques, or coracoclavicular repair technique and anterior to posterior temporary fixation with Kirschner wire toward the scapula, ${ }^{13}$ mostly used two clavicular tunnels to repair coracoclavicular ligaments. (Table 4) There was no difference between the proportion of specialists and generalists regarding the number of tunnels used.

Table 1. Absolute and relative frequency of surgery for acute ACD performed the previous year between specialists and non-specialists. ${ }^{\dagger}$ Descriptive level of probability of the chi-square test.

\begin{tabular}{|c|c|c|c|c|c|c|}
\hline & \multicolumn{4}{|c|}{ Specialist } & \multirow{3}{*}{$p$} \\
\hline & & \multicolumn{2}{|c|}{ Yes } & \multicolumn{2}{|c|}{ No } & \\
\hline & & $n$ & $\%$ & $n$ & $\%$ & \\
\hline \multirow{3}{*}{$\begin{array}{l}\text { Number of acute ACD } \\
\text { surgeries performed } \\
\text { (previous year) }\end{array}$} & Up to 5 & 5 & 16.7 & 31 & 68.9 & \\
\hline & 6 to 10 & 15 & 50.0 & 13 & 28.9 & $<0.001^{\dagger}$ \\
\hline & More then 10 & 10 & 33.3 & 1 & 2.2 & \\
\hline
\end{tabular}

Table 2. Absolute and relative frequency of the time of acquisition of the Orthopedics and Traumatology Specialist title (OTS-SBOT) among specialists and non-specialists. ${ }^{\dagger}$ Descriptive level of probability of the chi-square test.

\begin{tabular}{c|c|c|c|c|c|c}
\hline \multicolumn{2}{c|}{} & \multicolumn{4}{|c|}{ Specialist } & \multirow{2}{*}{$\boldsymbol{p}$} \\
\cline { 3 - 6 } \multicolumn{2}{c|}{} & \multicolumn{2}{|c|}{ Yes } & \multicolumn{2}{c}{ No } & \\
\cline { 2 - 6 } & $\mathbf{n}$ & $\%$ & $\mathbf{n}$ & $\%$ & \\
\hline \multirow{3}{*}{$\begin{array}{c}\text { OTS-SBOT } \\
\text { (years) }\end{array}$} & Up to 5 & 12 & 40.0 & 19 & 42.2 & \\
\cline { 2 - 6 } & 6 to 10 & 8 & 26.7 & 12 & 26.7 & $0.938^{\dagger}$ \\
\cline { 2 - 6 } & More then 10 & 10 & 33.3 & 13 & 28.9 & \\
\hline
\end{tabular}

In cases where the acromioclavicular joint was temporarily fixated with intramedullary Kirschner wire (Phemister's technique and its modifications) or anteroposterior toward the scapula, ${ }^{13}$ no difference regarding burying or not the Kirschner wire into the patient's subcutaneous tissue was observed between specialists and generalist, as well as the time of permanence of Kirschner wire. (Table 5) However, most surgeons, specialists or generalists, preferred to remove the Kirschner wire after six to eight weeks.

Half of the specialists used to pass the repair of coracoclavicular ligaments through the clavicle tunnel using a Ethibond ${ }^{T M}$ thread needle (Ethicon Inc, NJ, USA); while the other half passed it

Table 3. Absolute and relative frequency of the preferred surgical technique among specialist and non-specialist surgeons. ${ }^{\dagger}$ Descriptive level of probability of the exact Fisher's test.

\begin{tabular}{|c|c|c|c|c|c|c|}
\hline & \multicolumn{4}{|c|}{ Specialist } & \multirow{3}{*}{$p$} \\
\hline & & \multicolumn{2}{|c|}{ Yes } & \multicolumn{2}{|c|}{ No } & \\
\hline & & $\mathbf{n}$ & $\%$ & $\mathrm{n}$ & $\%$ & \\
\hline \multirow{8}{*}{ Technique } & Phemister's with suture-anchor & 5 & 16.7 & 16 & 35.6 & \\
\hline & Anteroposterior Kirschner wire & 7 & 23.3 & 9 & 20.0 & \\
\hline & Phemister's with wiring & 6 & 20.0 & 8 & 17.8 & \\
\hline & Endobutton & 9 & 30.0 & 0 & 0.0 & $<0.001^{\dagger}$ \\
\hline & Clavicular hook plate & 0 & 0.0 & 9 & 20.0 & \\
\hline & Isolated anchor & 1 & 3.3 & 3 & 6.7 & \\
\hline & Endobutton with anchor & 2 & 6.7 & 0 & 0.0 & \\
\hline & Other techniques & 0 & 0.0 & 0 & 0.0 & \\
\hline
\end{tabular}

Table 4. Absolute and relative frequency of the number of tunnels used to repair coracoclavicular ligaments of Phemister's modified technique. 'Descriptive level of probability of the exact Fisher's test.

\begin{tabular}{|c|c|c|c|c|c|c|}
\hline & \multicolumn{4}{|c|}{ Specialist } & \multirow{3}{*}{$p$} \\
\hline & & \multicolumn{2}{|c|}{ Yes } & \multicolumn{2}{|c|}{ No } & \\
\hline & & $\mathrm{n}$ & $\%$ & $\mathrm{n}$ & $\%$ & \\
\hline \multirow{4}{*}{ Number of tunnels } & 1 & 0 & 0 & 0 & 0.0 & \\
\hline & 2 & 13 & 61.9 & 21 & 58.3 & $0.598^{\dagger}$ \\
\hline & 3 & 8 & 38.1 & 12 & 33.3 & \\
\hline & 4 & 0 & 0.0 & 3 & 8.3 & \\
\hline
\end{tabular}

Table 5. Absolute and relative frequencies of the number of surgeons who buried and did not bury the Kirschner wire under the cutaneous tissue in cases of temporary fixation of the acromioclavicular joint and permanence of the Kirschner wire and the number of surgeons who buried and did not bury the Kirschner wire under the cutaneous tissue in cases of temporary fixation of the acromioclavicular joint. Descriptive level of probability of the chi-square test.

\begin{tabular}{|c|c|c|c|c|c|c|}
\hline & \multicolumn{4}{|c|}{ Specialist } & \multirow{3}{*}{$p$} \\
\hline & & \multicolumn{2}{|c|}{ Yes } & \multicolumn{2}{|c|}{ No } & \\
\hline & & $\mathrm{n}$ & $\%$ & $\mathrm{n}$ & $\%$ & \\
\hline \multirow{2}{*}{ Burying of Kirschner wire } & Yes & 11 & 57.9 & 17 & 50.0 & $0.581^{\dagger}$ \\
\hline & No & 8 & 42.1 & 17 & 50.0 & \\
\hline \multirow{6}{*}{$\begin{array}{l}\text { Time of permanence of } \\
\text { Kirschner wire (weeks) }\end{array}$} & 4 & 0 & 0.0 & 3 & 6.7 & \\
\hline & 5 & 0 & 0.0 & 1 & 2.2 & \\
\hline & 6 & 9 & 47.4 & 18 & 40.0 & $0.617^{\dagger}$ \\
\hline & 7 & 0 & 0.0 & 1 & 2.2 & \\
\hline & 8 & 9 & 47.4 & 10 & 22.2 & \\
\hline & 10 & 1 & 5.2 & 1 & 2.2 & \\
\hline
\end{tabular}


through Aciflex ${ }^{\text {TM }}$ wire (Ethicon Inc, NJ, USA). This wire was hardly used by generalists, which mostly used Ethibond ${ }^{\text {TM }}$ wire needle. Only one non-specialist used cerclage wire, and one non-specialist used nylon wire. (Table 4) For closing the deltotrapezoidal fascia, Vicryl ${ }^{\top m}$ thread (Ethicon Inc - NJ, USA) was preferred by most specialist or not specialist surgeons, followed by Ethibond ${ }^{\text {TM }}$ wire. A minority of specialists used wire Fiber Wire ${ }^{\circledR}$ (Arthrex, Inc. - FL, USA), and no one used nylon; while the minority of generalists used nylon wire, but no one used Fiber Wire ${ }^{\circledR}$. (Table 6)

\begin{tabular}{|c|c|c|c|c|c|c|}
\hline & & \multicolumn{4}{|c|}{ Specialist } & \multirow{3}{*}{$p$} \\
\hline & & \multicolumn{2}{|c|}{ Yes } & \multicolumn{2}{|c|}{ No } & \\
\hline & & $\mathrm{n}$ & $\%$ & $\mathrm{n}$ & $\%$ & \\
\hline \multirow{4}{*}{$\begin{array}{l}\text { Method to pass } \\
\text { the wire to repair } \\
\text { coracoclavicular } \\
\text { ligaments }\end{array}$} & Ethibond ${ }^{\mathrm{TM}}$ needle & 10 & 50.0 & 25 & 55.6 & \\
\hline & Aciflex ${ }^{\mathrm{TM}}$ & 10 & 50.0 & 7 & 15.6 & \\
\hline & Cerclage wire & 0 & 0.0 & 1 & 2.2 & $0.011^{\dagger}$ \\
\hline & Nylon wire & 0 & 0.0 & 1 & 2.2 & \\
\hline \multirow{4}{*}{$\begin{array}{l}\text { Wires used } \\
\text { for closing the } \\
\text { deltotrapezoidal } \\
\text { fascia }\end{array}$} & Vicryl $^{\mathrm{TM}}$ & 17 & 56.7 & 25 & 55.6 & \\
\hline & Ethibond ${ }^{\mathrm{TM}}$ & 8 & 26.7 & 14 & 31.1 & \\
\hline & Nylon & 0 & 0.0 & 6 & 13.3 & $0.007^{\dagger}$ \\
\hline & Fiber wire $^{\circledR}$ & 5 & 16.7 & 0 & 0.0 & \\
\hline
\end{tabular}

\section{DISCUSSION}

Surgical treatment of acute ACD can be done in different ways, with similar clinical outcomes. ${ }^{1-3,5,7-9}$ As the specialization in shoulder surgery and elbow internship aims to improve the technical and technological capabilities of the orthopedic surgeon, it has been questioned whether this specialization influences the preference for the technique used on surgical treatment of acute ACD.

In this study, the time of Orthopedists and Traumatology Specialists (OTS) according to the criteria of the Brazilian Society of Orthopedics and Traumatology (SBOT) and generalist were similar, which reduces the influence of surgical experience and improves the correlation of the findings with the academic background. Despite the similarity, specialists operated more acute ACD cases the previous year, suggesting that these cases were selected to be treated by specialists.

No non-specialist orthopedic surgeon used the endobutton technique, and some were even unfamiliar with it (data not shown). On the contrary, no specialists used hook clavicular plate, while this practice is adopted by $20 \%$ of generalists. Despite the fact that endobutton may cause an inflammatory reaction, ${ }^{14}$ the non-use of this plate by specialists may be motivated by the recognized need for its removal when it causes discomfort to the patient. ${ }^{3}$ Temporary fixation of anterior to posterior Kirschner wire toward the scapula was adopted by $23.3 \%$ of specialists and $20 \%$ of generalists. This is not an established technique as Phemister's, but it has been described by surgeons in charge of specialized services on our midst. ${ }^{13}$ These findings reinforce the influence of academic training in surgical preference.

In accordance with this fact, some technical details were preferred by specialists as compared to generalists, as the largest proportion of Aciflex ${ }^{\text {TM }}$ users to pass the repair of coracoclavicular ligaments through the clavicle tunnels, and Fiber Wire ${ }^{\circledR}$ for closing the deltotrapezoidal fascia; whereas, among the generalists, there was a greater proportion of cerclage wire or nylon users to repair coracoclavicular ligaments through clavicle tunnels, and nylon wire for closing the deltotrapezoidal fascia. The higher cost of Aciflex ${ }^{\mathrm{TM}}$ and Fiber Wire ${ }^{\circledR}$ inhibits their use mainly in public hospitals, where most of the training of specialists and generalists orthopedists is done. It is believed that specialists have more contact with these technologies and suppliers of these materials, justifying their increased use in acute ACD surgeries.

Despite the observed differences, most specialists used the same amount of tunnels to repair coracoclavicular ligaments as generalists. Most individuals in both groups also used the same passage technique to repair such ligaments. The rationale for conducting two transclavicular tunnels is given by the existence of two coracoclavicular ligaments; however, no studies were found comparing the use of one to four tunnels for the same technique. ${ }^{15,16}$

There was also consensus on: the wire used for closing the deltotrapezoidal fascia; the length of Kirschner permanence; and the choice of burying or not the Kirschner wire into the subcutaneous tissue. These preferences were justified by the known time of six to eight weeks for stabilization of the acromioclavicular joint and concerns regarding postoperative infection of the Kirschner wire orifice. ${ }^{17,18}$

Interestingly, although there are studies showing similar clinical and radiological results as to open techniques, not even specialists used minimally invasive or arthroscopic techniques. , $^{3,4,10,19,20}$ The non-availability of suitable material at the hospital, lack of training during specialization, long learning curve and increased surgical time may justify the non-use of these techniques. However, some technical details were not influenced by specialization. Moreover, even with specialization, shoulder and elbow surgeons do not perform minimally invasive or arthroscopic surgery. Further research may lead to a better understanding of the reasons, as well as regarding the correlation of surgical preference with clinical and radiographic results.

\section{CONCLUSION}

Based on the findings of this study, we concluded that specialization in shoulder and elbow surgery changes the orthopedists' preference on the technique used in the surgical treatment of acute ACD.

AUTHORS' CONTRIBUTIONS: Each author individually and contributed significantly to the development of the study. AYN (0000-0002-6451-8488)* CVBG (0000-0002-1659-6772)* and LP (0000-0001-9914-4327)* were the main contributors in drafting the manuscript. AYN, DSA (0000-0002-42382698)* and DLCM (0000-0002-8313-595X)* applied the questionnaires. AYN, DLCM, CVBG LP and evaluated the data of the statistical analysis. AYN, DSA, CVBG, RRB (0000-0001-9581-3239* and LP and performed the literature search, reviewed the manuscript and contributed to the intellectual concept of the study. All authors contributed to the intellectual concept of the study. ${ }^{*}$ ORCID (Open Researcher and Contributor ID). 


\section{REFERENCES}

1. Beitzel K, Cote MP, Apostolakos J, Solovyova O, Judson CH, Ziegler CG, et al. Current concepts in the treatment of acromioclavicular joint dislocations. Arthroscopy. 2013;29(2):387-97.

2. Läderman A, Grosclaude M, Lübekke A, Christofilopoulos P, Stern R, Rod T, et al.Acromioclavicular and coracoclavicular cerclage reconstruction for acute acromioclavicular joint dislocations. J Shoulder Elbow Surg. 2011;20(3):401-8.

3. Metzlaff S, Rosslenbroich S, Forkel PH, Schliemann B, Arshad H, Raschke $\mathrm{M}$, et al.Surgical treatment of acute acromioclavicular joint dislocations: hook plate versus minimally invasive reconstruction. Knee Surg Sports Traumatol Arthrosc. 2016;24(6):1972-8.

4. Rosslenbroich SB, Schliemann B, Schneider KN, Metzlaff SL, Koesters CA, Weimann A, et al. Minimally invasive coracoclavicular ligament reconstruction with a Flip-Button technique (MINAR): clinical and radiological midterm results. Am J Sports Med. 2015;43(7):1751-7.

5. Sobhy MH. Midterm results of combined acromioclavicular and coracoclavicular reconstruction using nylon tape. Arthroscopy. 2012;28(8):1050-7.

6. Struhl S, Wolfson TS. Continuous loop double endobutton reconstruction for acromioclavicular joint dislocation. Am J Sports Med. 2015;43(10):2437-44.

7. Horst K, Dienstknecht T, Andruszkow H, Gradl G, Kobbe P, Pape HC. Radiographic changes in the operative treatment of acute acromioclavicular joint dislocation tight rope technique vs. K-wire fixation. Pol J Radiol. 2013;78(4):15-20.

8. Millett PJ, Horan MP, Warth RJ. Two-year outcomes after primary anatomic coracoclavicular ligament reconstruction. Arthroscopy. 2015;31(10):1962-73.

9. Yoon JP, Lee BJ, Nam SJ, Chung SW, Jeong WJ, Min WK, et al. Comparison of results between hook plate fixation and ligament reconstruction for acute unstable acromioclavicular joint dislocation. Clin Orthop Surg. 2015;7(1):97-103.

10. Helfen T, Siebenbürger G, Ockert B, Haasters F. Therapy of acute acromioclavicular joint instability. Meta-analysis of arthroscopic/minimally invasive versus open procedures. Unfallchirurg. 2015;118(5):415-26.

11. Phemister DB. The treatment of dislocation of the acromioclavicular joint by open reduction and threaded-wire fixation. J Bone Joint Surg Am. 1942;24(1):166-8.

12. Dlabach JA. Acute Dislocation In: Canale ST, Beaty JH. Campbell's operative orthopaedics. 11th ed. Philadelphia: Mosby Elsevier; 2008. p. 3586-92.

13. Carrera EF, Pierami R, Sugawara MJ, Nicolao FA, Netto NA, Matsumoto MH. Evaluation of the surgical treatment of acromioclavicular joint dislocation with a new option for temporary fixation of the acromioclavicular joint. Tech Shoulder Elbow Surg. 2013;14:99-103.

14. Woodmass JM, Esposito JG, Ono Y, Nelson AA, Boorman RS, Thornton GM, et al. Complications following arthroscopic fixation of acromioclavicular separations: a systematic review of the literature. Open Access J Sports Med. 2015;6:97-107.

15. Coale RM, Hollister SJ, Dines JS, Allen AA, Bedi A. Anatomic considerations of transclavicular-transcoracoid drilling for coracoclavicular ligament reconstruction. J Shoulder Elbow Surg. 2013;22(1):137-44.

16. Hou Z, Graham J, Zhang Y, Strohecker K, Feldmann D, Bowen TR, et al. Comparison of single and two-tunnel techniques during open treatment of acromioclavicular joint disruption. BMC Surg. 2014;14:53.

17. Leidel BA, Braunstein V, Kirchhoff C, Pilotto S, Mutschler W, Biberthaler P. Consistency of long-term outcome of acute Rockwood grade III acromioclavicular joint separations after K-wire transfixation. J Trauma. 2009;66(6):1666-71.

18. Leidel BA, Braunstein V, Pilotto S, Mutschler W, Kirchhoff C. Mid-term outcome comparing temporary K-wire fixation versus PDS augmentation of Rockwood grade III acromioclavicular joint separations. BMC Res Notes. 2009;2:84.

19. Izadpanah K, Jaeger M, Ogon P, Südkamp NP, Maier D. Arthroscopically Assisted Reconstruction of Acute Acromioclavicular Joint Dislocations: Anatomic AC Ligament Reconstruction With Protective Internal Bracing-The "AC-RecoBridge" Technique. Arthrosc Tech. 2015;4(2):e153-61.

20. Spoliti M, De Cupis M, Via AG, Oliva F. All arthroscopic stabilization of acute acromioclavicular joint dislocation with fiberwire and endobutton system. Muscles Ligaments Tendons J. 2015;4(4):398-403.

\section{Annex 1. Questionnaire on the surgical technique used to repair acute acromioclavicular dislocation.}

1. Did you operate any acute ACD last year?

$\square$ Yes

$\square$ No

2. How many acute ACD did you operate last year?
$\square$ Up to 5
More than 10
6-10

3. Time from obtaining the title Orthopedics and Traumatology Specialist by SBOT (years)?
$\square$ Up to 5
More than 10
6-10

4. How long have you been practicing shoulder and elbow surgery?

$\square$ Up to 5

More than 10

6-10

5. Which technique do you use to repair acute ACD?

$\square$ Phemister's with wiring for coracoclavicular ligaments

$\square$ Phemister's with anchor for coracoclavicular ligaments

$\square$ Repair of coracoclavicular with anchor and anteroposterior Kirschner wire (from clavicle to scapula)
Hook clavicular plate

Endobutton

Endobutton with anchor

Other techniques, please specify:

6. For techniques that repair coracoclavicular ligaments (Phemister's modified, or Kirschner wire fixation, anterior to posterior), how many tunnels do you use in the clavicle? $\square 1$ 2

$\square 3$

$\square 4$

7. Do you burry Kirschner wire or leave it exposed on the patient's skin?

Yes, I burry

No, I do not burry

8. In how much time do you remove the Kirschner wire (weeks)? 4

5

$\square 6$

$$
\begin{aligned}
& \square 7 \\
& \square 8 \\
& \square 10
\end{aligned}
$$

9. How do you perform the passage of wires to repair coracoclavicular ligaments through tunnels?

Ethibond $^{\mathrm{TM}}$ wire needle

Aciflex ${ }^{\mathrm{TM}}$

$\square$ Cerclage wire

Nylon wire

10. Which wire do you use to close the deltotrapezoidal fascia?
Vicryl $^{\mathrm{TM}}$
Ethibond"
Nylon wire
Fiber wire ${ }^{\circledR}$ 